\title{
Usage of Tonaton.Com by Buyers and Sellers: A Survey of Car Dealers in Kumasi Metropolis
}

\author{
Appiahene Peter \\ Masters Student, IT \\ Kwame Nkrumah University of \\ Science and Technology \\ Kumasi, Ghana
}

\author{
Opoku Michael \\ Masters Student, IT \\ Kwame Nkrumah University of \\ Science and Technology \\ Kumasi, Ghana
}

\author{
Alorwu D.K. Daniel \\ Masters Student, IT \\ Kwame Nkrumah University of \\ Science and Technology \\ Kumasi, Ghana
}

\begin{abstract}
ABSTARCT
Tonaton.com is a classified advertisements website operating in Ghana. The website was officially and formally launched to begin operation in Ghana on the 23rd April 2013. Tonaton", with its meaning in our local language as "Buy and Sell" in Asante Kasa Twi, tries to find and provide a trustworthy medium for the buying and selling of products and services. This paper seeks to analyze the usage of the Tonato.com website to see if car buyers and sellers in Kumasi Metropolis are making good use of it. A survey of car dealers in Kumasi Metropolis in the Ashanti Region of Ghana was conducted. Five garages in the Kumasi Metropolis were randomly selected using Systematic random sampling. Two hundred and fifty respondents were selected from these five garages using cluster random sampling and questionnaires were distributed among the respondents and out of which 235 responded to the questionnaires. This means that the rate of response of the study was 94 percent. The data were analyzed by using Statistical Package for the Social Sciences (SPSS) latest version. Results were also presented in tables and different figures. After the survey, the responses gathered shows that few of them believe that Tonaton.com is not real whiles a vast number of them have confidence in Tonaton.com and they have been using Tonaton.com daily and mostly for their car businesses with a percentage of $75.74 \%$.It was also discovered after the study that they also use it for other activities like looking for apartment to buy or rent and looking for lands and other properties to buy.
\end{abstract}

\section{General Term}

Web Technology

\section{Keywords}

Tonaton.Website, SPSS, Survey, Dealers, Buyers, Sellers

\section{INTRODUCTION}

Website is often seen in this information era as a facilitator for change, change in business transactions, change in marketing thus buying and selling and searching for product and services which we normally call "window shopping"[1]. Website normally defined as is a set of related web pages served from a single web domain. A website is hosted on at least one web server, accessible via a network such as the Internet or a private local area network through an Internet address known as a Uniform resource locator(URL). All publicly accessible websites collectively constitute the World Wide Web (www) [6].

Tonaton.com is atypical example of website and this site serves as a platform where products and services are advertised and the business transaction is completed by the old business method. Thus the business transaction is completed by the physical face -to face contact of customer experience.

According to Ghanaweb (2013) Tonaton.com is a classified advertisements website operating in Ghana. The website was officially and formally launches to begin operation in Ghana on the 23rd April 2013 [2].

According to Hammer (2013) "this simple, easy and costeffective service is set to revolutionize the classifieds industry in Ghana". He also stated that, "The Ghanaian market is developing at a phenomenal rate. This coupled with the increase in internet penetration and usage in the country indicates that we have plenty of opportunity in this country. As the country continues to grow and develop, Tonaton.com will grow parallel to it. As internet usage increases in schools, homes and among mobile phone users, we at Tonaton.com sees an opportunity to introduce something different, interesting and beyond traditional classified advertising to Ghanaians[2].

"Tonaton", with its meaning in our local language as "Buy and Sell" in Asante Kasa Twi, tries to find and provide a trustworthy medium for the buying and selling of products and services. The site allows users to seamlessly upload ads onto the site and have them displayed within some few hours of posting. The ads normally go through a rigorous endorsement procedure, makes sure that they follow the terms and conditions to ensure the products and services sold are genuine and as open as possible [10].

\subsection{Aims of the Study}

The main objectives of the study were to analyze the pattern of Tonaton.com usage by car dealers and sellers, its availability, use of Tonaton by their customers during business transactions, car dealer's knowledge of different ecommerce sites and their opinion about Tonaton use in marketing. Moreover, effort was made to also investigate the:

\footnotetext{
* The drive for internet use by respondents

* Impact of Tonaton on their business

* level of their information retrieval skills on Tonaton

* commonly used website by respondents

* time spent by the respondents in Tonaton information searching activities

* Problem encountered by these respondents in accessing Tonaton and other online advertisement.
} 


\section{RESEARCH METHODOLOGY}

The authors designed a questionnaire after given a brief introduction of Tonaton.com and its potential benefits to buyers and sellers. Some background history of Tonaton.com was also considered. A survey of car dealers in Kumasi Metropolis in the Ashanti Region of Ghana was conducted. Five garages in the Kumasi Metropolis were randomly selected using Systematic random sampling and the garages are: Asokwa gareges,Suame roundabout garages, Bekwai roundabout garages, Ahodwo roundabout garages and Santasi roundabout garages. Two hundred and fifty respondents were selected from these five garages using cluster random sampling and questionnaires were distributed among the respondents and out of which 235 responded to the questionaires. Which means that the rate of response of the study was 94 percent. The data were analyzed by using Statistical Package for the Social Sciences (SPSS) latest version. Results were also presented in tables and different figures.

\subsection{Background History of Tonaton.com and its Benefits to buyers and sellers}

Tonaton.com which is a locally made Ghanaian website with its name originating from a Ghanaian linguistic called Twi and which simply means "Buy and sell". It was official lunched in Ghana on 23rd April 2013 by the Chief Executive Officer, Nils Hammar. This website is own by a Swedish investment company Kinnevik AB. They are also owners of other well-known Ghanaian brands such as Tigo and Viasat 1.The following are some of the benefits of Tonaton.com to buyers and sellers in Ghana:

* Online Branding of products and services

* Meet Changing Demands by customers

* Consumer Preferences is also increase as they have many options to choose from

* Cost Efficiency by customers in looking for cars to buy. They can just sit in their houses and search for items online

* Increase Sales for sellers.

* Always Available to Consumers irrespective of the day and time.

* Maintain Communication as buyers normally leave their contacts online for easy communication [5].

\section{A view of tonaton.com website}

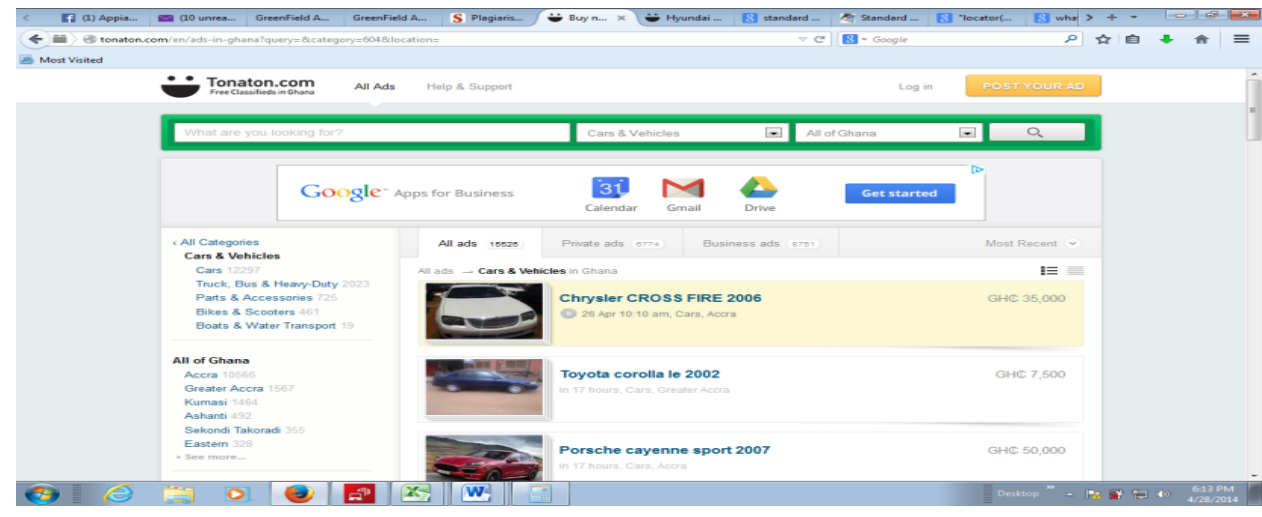

Figure 1. A view of tomato.com website with display cars source (tonaton.com)

\section{DATA ANALYSIS}

\subsection{Respondent's Garages}

Two hundred and fifty car dealers were selected for obtaining data from car dealers in Kumasi Metropolis. From the total 235 who responded to the questionnaire, 75 (31.91\%) respondents were from Suame Roundabout, 55 (23.40\%) were from Bekwai roundabout,34 (14.47\%) respondents were from Santasi roundabout,39(16.60\%) were from Ahodwo roundabout and 32 (13.62) were also from Asokwa roundabout (See $\quad$ Figure

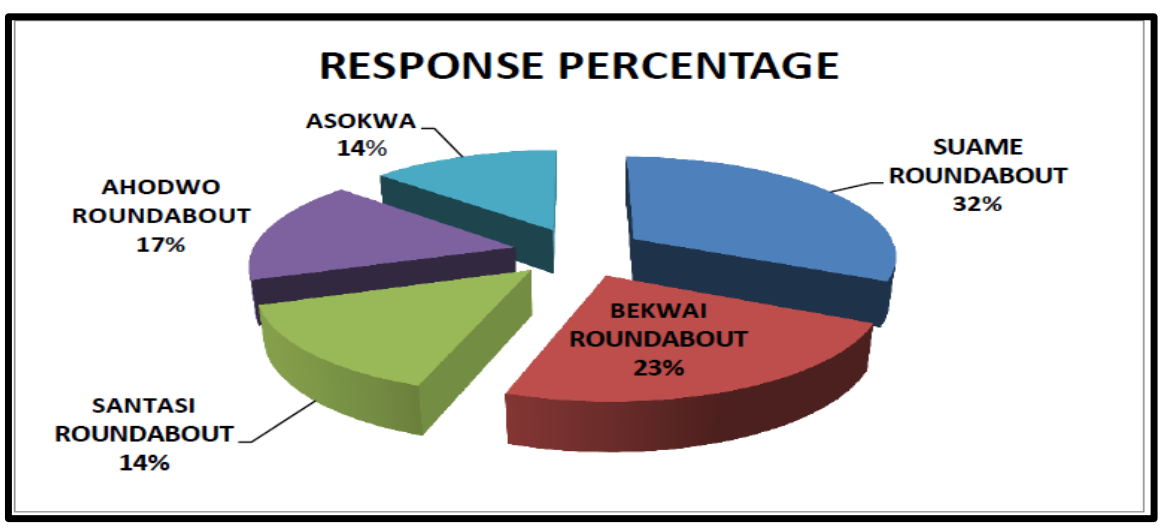

Figure 2. Pie graph showing Respondents percentage according to Garages 


\subsection{Respondent's Age}

The analysis of the data shows that $154(65.53 \%)$ respondents were between 35 to 45 years old, $60(25.53 \%)$ were between 46 to 55 years and $21(8.94 \%)$ respondents was above 55 years old.

\subsection{Availability of Tonaton website to Respondents}

Figure 2 shows that a good number of the respondents numbering $118(50.21 \%)$ access the Tonaton website on their phones , $45(19.15 \%)$ respondents access it at the cafe, 31 $(13.19 \%)$ respondents use ipad and tablets, and $41(17.45 \%)$ respondents use it at their friend's home.

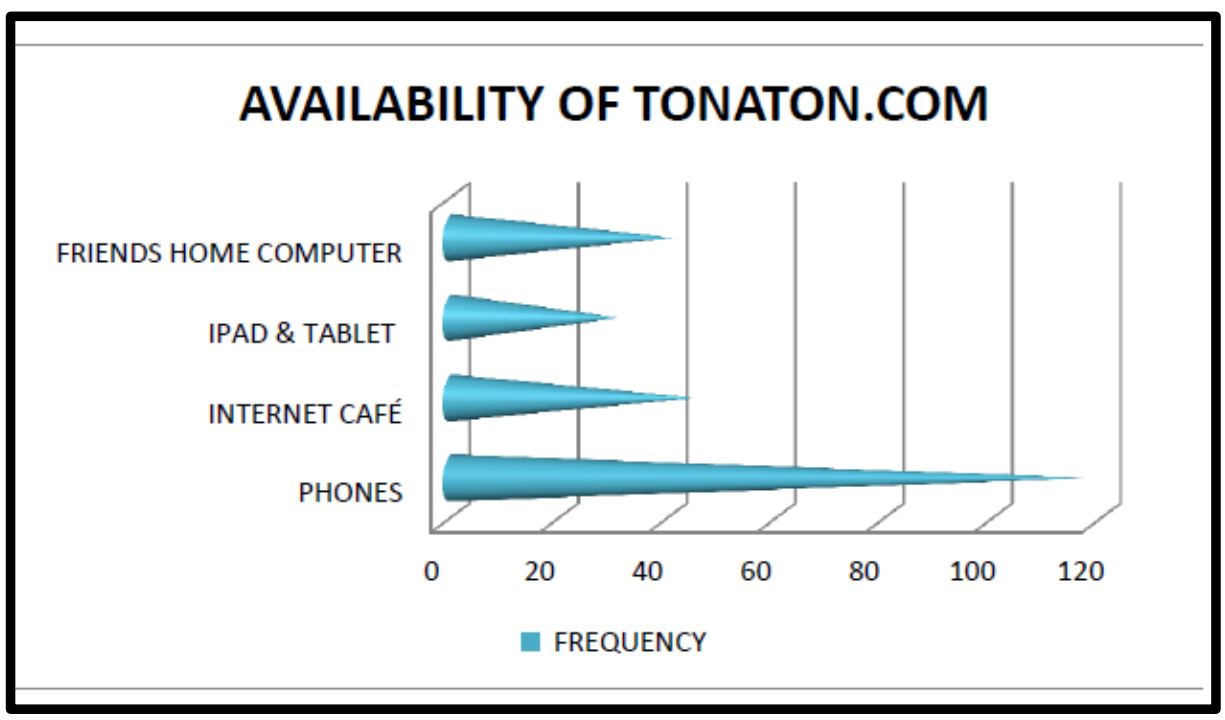

Figure 3. A bar graph showing the availability of tonaton.com to Respondents

\subsection{Use of Tonaton.com by customers}

Respondents were ask on how often their customers use Tonaton.com when looking for their favorite cars and most of them said (Mean= 2.49) that their customers Always use Tonaton.com when looking for cars to buy.

Table1. Statistical Distribution of Tonaton.com Use By Customers when looking for a car to buy.

\begin{tabular}{|l|l|l|l|l|l|}
\hline Sr. & Tonaton.com Use & Mean & Median & Mode & Std. \\
\hline 1. & Use of tonaton.com by car buyers & 2.49 & 3.00 & 3.00 & 10.21 \\
\hline
\end{tabular}

Key: 1 Represent Never, 2 Stands for Sometimes and 3= Always

\subsection{Respondent's Knowledge of Tonaton Website}

Respondent's knowledge of Tonaton website was analyzed. It was disclosed that a chunk of the respondents are quite confident in using Tonaton.com. Use of the homepage (mean= $3.15)$, how to search for products and services (Mean=3.09), uploading add $($ mean= 2.64), Editing add $($ mean= 2.59), creating email and using it on tonaton.com (mean= 2.83), Deleting Add (mean= 2.81) Scrolling through Ad, Moving from one page to another Table

Table 2. Statistical Distribution of Respondent's Knowledge of Tonanto.com

\begin{tabular}{|l|l|l|l|l|l|}
\hline Sr. & Buyers \& Sellers Knowledge of Tonaton.com & Mean & Median & Mode & Std. \\
\hline 1. & Use of the homepage & 3.15 & 3.00 & 4 & .957 \\
\hline 2. & Searching for products and services & 3.09 & 3.00 & 4 & .983 \\
\hline 3. & Uploading Advert & 2.64 & 3.00 & 3 & 1.063 \\
\hline 4. & Editing Advert & 2.59 & 3.00 & 3 & 1.137 \\
\hline 5. & Creating email \& using it on tonaton.com & 2.83 & 3.00 & 3 & 1.077 \\
\hline 6. & Deleting Advert & 2.81 & 3.00 & 4 & 1.071 \\
\hline 7. & Scrolling through Advert & 2.58 & 2.00 & 3 & 1.915 \\
\hline 8. & Moving from one page to another & 2.31 & 2.00 & 2 & 1.063 \\
\hline
\end{tabular}

Key: 1 stands for Not Self-confident, 2 for Self-confident, 3 represent Quite Self-confident, and 4 goes Very Self-confident 


\subsection{Respondent's Opinion about Tonaton.com Use in buying and selling}

Respondents were asked to give their various impressions about the usage of Tonaton.com in buying and selling. Majority of them strongly believe thatTonaton.com have great impact on buying and selling $($ mean $=4.18)$, Tonaton.com promotes buying and selling $($ mean $=4.00)$, Tonaton.com increase revenue $($ mean $=3.47)$, customers should use Tonaton.com when looking for cars to buy $($ mean $=3.84)$, use of Tonaton.com for searching for cars is better than moving from garage to garage (mean= 3.69) while most of the respondent did not give their impressions regarding the following statements: I feel fear from the using of Tonaton.com $($ mean $=2.87)$, I know how to use Tonaton.com but feels lazy in using it for doing car business (mean=3.31), I think meeting customers face to face is better than Tonaton.com $($ mean= 3.46), I cannot do business outside Kumasi without the use of Tonaton.com $($ mean= 3.12), I wish thatTonaton.com should not be used in selling cars (mean= 2.02), I find it sometimes waste of time to use Tonaton.com in business (mean= 3.14) and some responded as I don't think Tonaton.com is real $($ mean $=3.18)$.

Table.3 Respondents Opinion about Tonato.com Use

\begin{tabular}{|l|l|l|l|l|l|}
\hline Sr. & Respondents Opinion about Tonato.com Use & Mean & Median & Mode & Std. \\
\hline 1. & Tonaton.com has great impact on buying and selling & 4.18 & 4.00 & 4 & .724 \\
\hline 2. & Tonaton.com promotes buying and selling & 4.00 & 4.00 & 4 & .739 \\
\hline 3. & Tonaton.com increase revenue & 3.47 & 4.00 & 4 & .905 \\
\hline 4. & Customers should use Tonaton.com when looking for cars to buy & 3.84 & 4.00 & 4 & 1.013 \\
\hline 5. & Use of Tonaton.com for searching for cars is better than moving from garage to garage & 3.69 & 3.00 & 2 & 1.258 \\
\hline 6. & I feel fear from the using of Tonaton.com & 2.87 & 3.00 & 4 & 1.186 \\
\hline 7. & I know how to use Tonaton.com but feels lazy in using in business & 3.31 & 4.00 & 4 & 1.108 \\
\hline 8. & I think meeting customers face to face is better than Tonaton.com & 3.46 & 4.00 & 4 & 1.217 \\
\hline 9. & I cannot do business outside Kumasi without the use of Tonaton.com & 3.12 & 3.00 & 3 & 2.777 \\
\hline 10. I wish thatTonaton.com should not be used in selling cars & 2.02 & 3.00 & 4 & 1.168 \\
\hline 11. I find it sometimes waste of time to use Tonaton.com in business & 3.14 & 3.00 & 2 & 1.361 \\
\hline 12. & I don't think Tonaton.com is real & 3.18 & 3.00 & 4 & 1.307 \\
\hline
\end{tabular}

Key: $1=$ Strongly Don't Believe, $2=$ Don't believe, $3=$ No Opinion, $4=$ Strongly Believe

\subsection{Tonaton.com use by respondents for different activities}

The author also tried to analyze the purpose of Tonaton.com use by respondents and a good number of them said that they use Tonaton.com for car business, number $=178(75.74 \%)$ while $31(13.19 \%)$ respondents use for looking for apartment,
$10(4.23 \%)$ respondents use for searching for land and building buying, $5(2.13 \%)$ for looking for car parts, 5 $(2.13 \%)$ respondents for looking for good institutions for their wards, and $6(2.55 \%)$ responded as for looking for computers and its accessories.

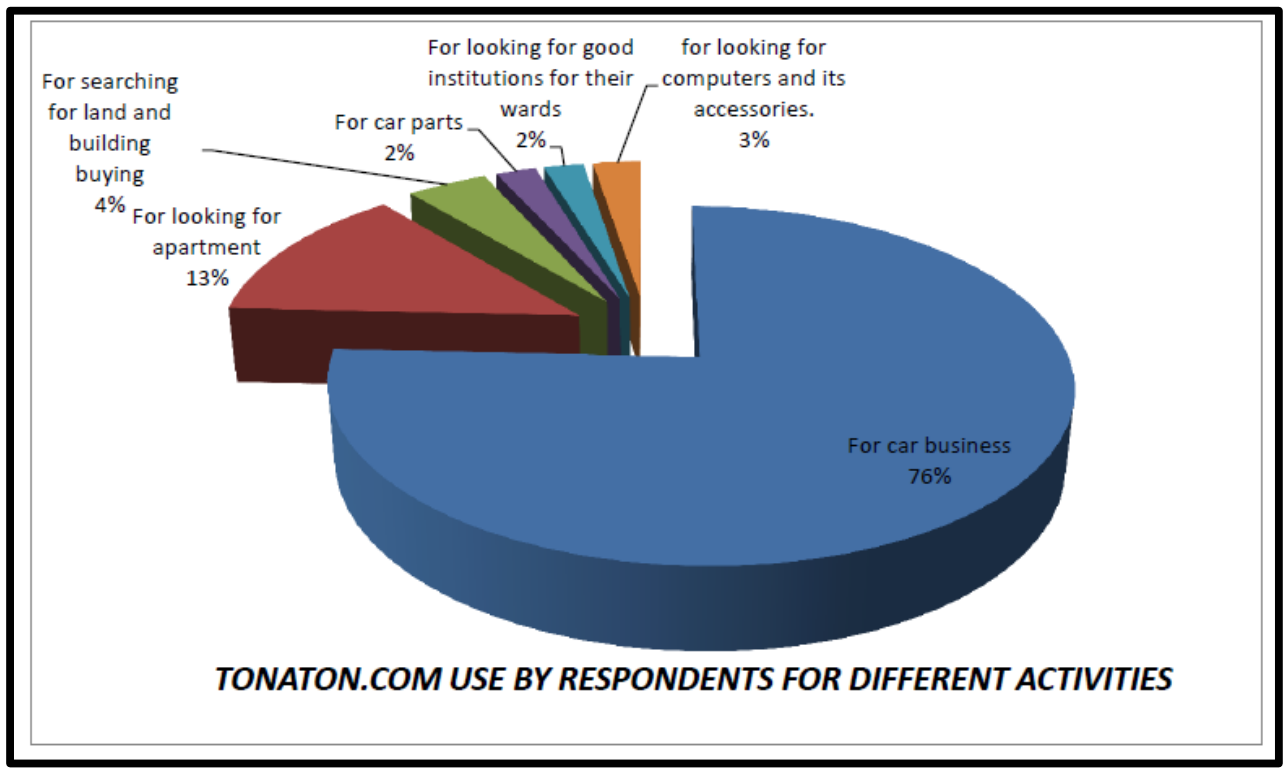

Figure 4. A chart showing other different usage of tonaton.com by Respondents by \% 


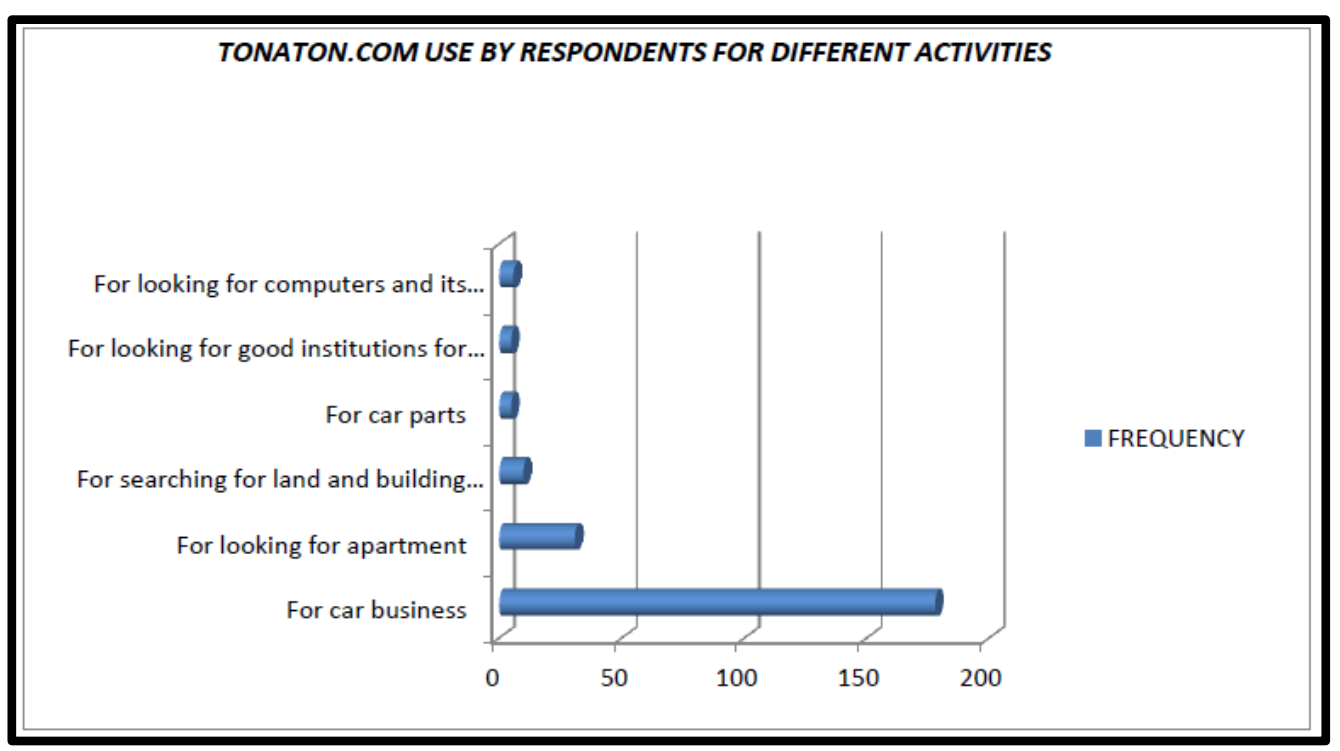

Figure 5. A graph showing other different usage of tonaton.com by Respondents by Frequency

\subsection{Major Findings of the Study}

* According to the all of the respondents was between 35 to 45 years old.

* A larger number also reported that they use Tonaton.com at their various garages.

* It was found that their customers sometimes make use of Tonaton.com when looking for car to buy.

* A good number of the respondent's knowledge about Tonaton.com was found quite sufficient for buying and selling purposes.

* Most of them strongly believe that Tonaton.com have great impact on their daily earnings.

* A significant number of them mentioned that they use Tonaton.com daily and mostly for car business.

The responses gathered also show that few of them believe that Tonaton.com is not real whiles a vast number of them have confidence in Tonaton.com.

\section{CONCLUSION}

The usage of Tonaton.com can promote significant changes in the business of buying and selling and is important to car dealers. In this paper, the respondents reported that their customers sometimes use Tonaton.com searching for cars. According to Hammer, 2013 "this simple, easy and costeffective service is set to revolutionize the classifieds industry in Ghana"[2]. Taking the importance of Tonaton.com into consideration, the study ended up that customers should make good use of Tonaton.com when searching for cars as it saves time and prevent them from unnecessary hardships.

\section{ACKNOWLEDGMENT}

Authors are thankful to Dr.J.B.H.Acquah Senior lecturer and former HOD of Computer Science Department of Kwame Nkrumah University of Science and Technology. We also thank Dr. Thomas Yeboah of Christian Service University College, Ruth Wiafe Akenteng and one lady by name Serwah Sandra all in Kumasi. Finally to Mr. and Mrs. Kofi Agyeman of USA.

\section{REFERENCES}

[1] 10 Reasons Internet Marketing is Important to Your Business | AGI Marketing Solutions | El Paso, Tx ,Retrieved December 9, 2013, from http://www.agims.com

[2] Tonaton.com launches free classifieds website in Ghana, Retrieved January 6 2014, from http://www.ghanaweb.com

[3] Auto Dealer Websites Ghana, Retrieved January10 2014, from http://aginto.com

[4] Ian Linton, Demand Media Six Benefits of Internet Marketing, Retrieved January10 2014, from http://smallbusiness.chron.com

[5] Jaydeep Dosi October 11, 20135 Important Internet Marketing Lessons from Steve Jobs Retrieved January10 2014, from http://www.searchenginejournal.com

[6] Website From Wikipedia, the free encyclopedia Retrieved January10 2014 from http://en.wikipedia.org

[7] Shane Diffily The Website Manager's Handbook an abridged extract from "Chapter 2: Website Maintenance" of The Website Manager's Handbook by :pp7-13

[8] M i c h a e 1 a. S t e 1 z n e r, May 2013: 2013 social media marketing industry report how marketers are using Social media to grow their businesses:pp17-41

[9] Zakaria, M. H., Watson, J. \& Edwards, S. L. (2010). Investigating the use of Web 2.0 technology by Malaysian students. Multicultural Education \& Technology Journal 4(1): pp17-29.

[10] Welcome to Tonaton.com - the largest marketplace in Ghana Retrieved January13 2014 from http://tonaton.com 